\title{
Campaign on Diabetes in Western Amazon 2017-2018: Analysis of Risk Factors for T2DM of participating population
}

\author{
Lucas Meira Emerenciano², Camila Flávia Matuda Cabral², Janaína Pereira da Silva², \\ Guilherme Augusto Vassoler Panuci ${ }^{2}$, Ana Carolina Rimoldi Fachinello², Carin Vanessa \\ Silva Schneider², Harissane Doráiny Santos², Brunna Yasmin Borges Lérias², Rafael \\ Carlos Puttin ${ }^{2}$, Janiely Silva Melo, Orlando Leite de Carvalho ${ }^{1},{ }^{2}$ \\ 1 Hospital Santa Marcelina, Brazil. \\ 2 Liga Acadêmica de Endocrinologia de Rondônia- LAEDRO
}

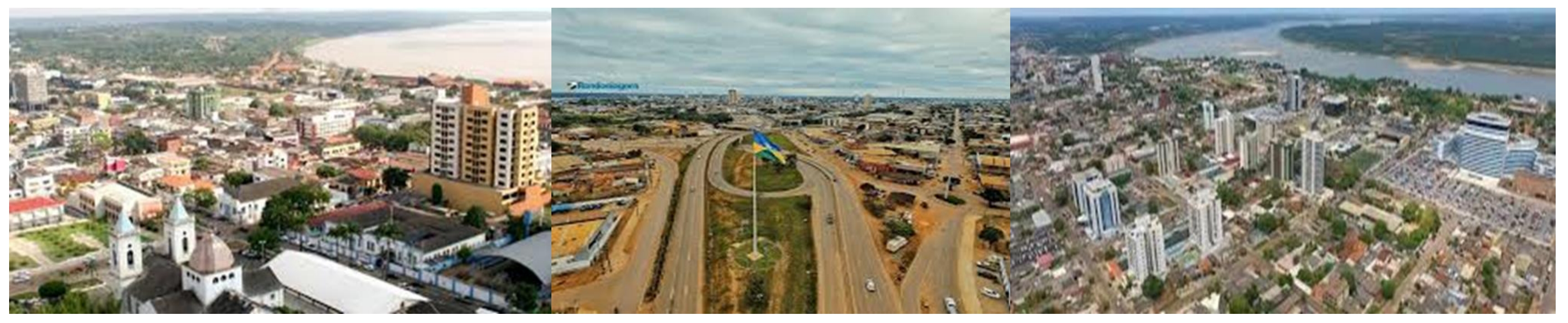

\begin{abstract}
Diabetes mellitus (DM) is a metabolic disease with multiple etiologies, caracterized as chronic, progressive and presents hyperglycemia as a result of carbohydrate, lipid and protein disorders ${ }^{1}$. Increase in incidence of this pathology in general population is associated with expansion of industrialization, higher consumption of hypercaloric diets, sedentary lifestyle, overweight, among others ${ }^{2}$. Type 2 DM (T2DM) is the most prevalent type, with about $90-95 \%$ of total cases and is related to the increase of insulin resistance and deficiency in secretion of this hormone ${ }^{3}$. The beginning of this disease is insidious, asymptomatic and associated with lifestyle of individuals with genetic predisposition. Therefore, investigating risk factors is an essential measure to develop future activities in health promotion and intervention ${ }^{4}$.
\end{abstract}

Analyze the incidence of risk factors for T2DM in participants of Diabetes Awareness Campaign of 2017 and 2018 in Porto Velho-RO, Brazil.

\section{Method}

In campaign held in Porto Velho - Rondônia, Brazil, a questionnaire was used to evaluate the most prevalent risk factors of T2DM in treatment based on Finnish Diabetes Risk Score. Risk factors assessed were: a) age >45 years; b) gender; c) Body Mass Index (BMI): adequate $\left(<25 \mathrm{~kg} / \mathrm{m}^{2}\right)$, overweight $\left(25-29,9 \mathrm{~kg} / \mathrm{m}^{2}\right)$, obesity $\left(\geq 30 \mathrm{~kg} / \mathrm{m}^{2}\right)$; d) frequency and duration of physical activity over the week; e) tabagism; f) previous diagnosis of systemic arterial hypertension (SAH); g) family history of DM; h) history of gestational DM and/or fetal macrosomia in women. There was no question about previous diagnosis of DM. Participants under 18 years old and pregnant women were excluded. Criteria for risk factors for T2DM were based on Brasilian Society of Diabetes 2017-2018.

\section{Results}

In total, 685 people were attended, being $50,65 \%$ men $(n=347)$ and $49,34 \%$ women $(n=338)$. Of these, 92,26\% ( $n=632)$ presented risk fators for T2DM, of which $48,73 \%$ were women $(n=322)$ and $51,26 \%$ men $(\mathrm{n}=324)$. The incidence of these factors was: BMI $\geq 25 \mathrm{~kg} / \mathrm{m}^{2}$ $74,36 \%(n=470)$; sedentary lifestyle 51,74\% ( $n=327)$; age $>45$ years $45,41 \%(\mathrm{n}=287)$; positive first-degree family history $35,28 \%(\mathrm{n}=223)$, tabagism 28,48\% ( $n=180)$; SAH 22,94\% ( $n=145)$, gestational DM and/or fetal macrosomia in women $5,27 \%(\mathrm{n}=17)$.

\section{Discussion}

There was a high incidence of risk factors for T2DM related to life habits evaluated by questionnaire applied in study population. Therefore, a precedente is opened for actions to promote and prevent health, in order to reduce such factors in this population.

\section{References}

1 - VILAR, Lucio. Endocrinologia clínica. 6 ed. Rio de Janeiro: Guanabara Koogan, 2016.

2 - HU, Frank B. (2011). Globalization of Diabetes: The role of diet, lifestyle, and genes. Diabetes care. 34. 1249-57. 10.2337/dc11-0442.

3 - American Diabetes Association. 2. Classification and Diagnosis of Diabetes: Standards of Medical Care in Diabetesd - 2019. Diabetes Care 2019;42(Suppl. 1):S13-S28. DOI: https://doi.org/10.2337/dc19S002.

4 - American Diabetes Association. 3. Prevention or Delay of Type 2 Diabetes: Standards of Medical Care in Diabetes - 2019. Diabetes Care 2019;42(Suppl. 1):S29-S33. DOI: https://doi.org/10.2337/dc19-S003.

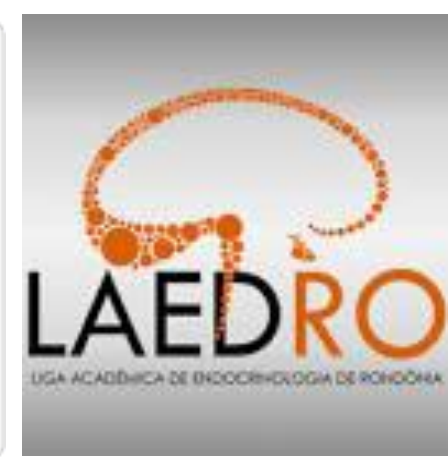

